\title{
An Ultrasensitive Method for Detecting Picomolar Levels of Cadmium(II) by Fast-Scan Anodic Stripping Voltammetry
}

\author{
Weiqiang Meng ${ }^{1}$, Peng Liu ${ }^{2}$, Pingru Cai ${ }^{1}$, Tingting Hao ${ }^{1}$, Shaohua Ma ${ }^{3}$, Yufang $\mathrm{Hu}^{1}$, Sui Wang ${ }^{1}$, \\ Yangbo $\mathrm{Wu}^{2, *}$ and Zhiyong Guo ${ }^{1, *}$ \\ ${ }^{1}$ School of Materials Science and Chemical Engineering, The State Key Laboratory Base of Novel \\ Functional Materials and Preparation Science, Ningbo University, Ningbo 315211, PR China \\ ${ }^{2}$ Faculty of Electrical Engineering and Computer Science, Ningbo University, Ningbo 315211, PR \\ China \\ ${ }^{3}$ School of Medical Technology, Ningbo College of Health Sciences, Ningbo 315100, PR China \\ *Email: wuyangbo@nbu.edu.cn, guozhiyong@nbu.edu.cn
}

doi: 1020964/2018.12.31

Received: 8 August 2018 / Accepted: 24 September 2018 / Published: 5 November 2018

\begin{abstract}
This work reported an approach for the determination of the heavy metal ion cadmium Cd(II) using a bismuth-film electrode (Bi-FE) with fast-scan anodic stripping voltammetry (FSASV). The experiment was divided into two steps. First, the Bi-FE was prepared by electrodepositing a metallic bismuth-film onto the electrode, and then the target metal ion $\mathrm{Cd}$ (II) was electrochemically preconcentrated on the Bi-FE. Second, the target metal was measured with FSASV. At a scan rate of $400 \mathrm{~V} / \mathrm{s}$, the anodic stripping peak current increased gradually with increasing $\mathrm{Cd}(\mathrm{II})$ concentration, and a linear relationship between the peak current and the logarithm of $\mathrm{Cd}(\mathrm{II})$ concentration was obtained from 0.1 $\mu \mathrm{mol} / \mathrm{L}$ to $1.0 \mathrm{pmol} / \mathrm{L}$, with a detection limit of $0.3 \mathrm{pmol} / \mathrm{L}(\mathrm{S} / \mathrm{N}=3)$. Furthermore, the method was successfully applied to detect $\mathrm{Cd}(\mathrm{II})$ in spiked tap water samples, with sufficient recoveries in the range of $94.0 \%$ to $105.2 \%$ and corresponding relative standard deviations ranging from $2.9 \%$ to $6.4 \%$. Therefore, FSASV is a simple, rapid and ultrasensitive method for the detection of picomolar levels of $\mathrm{Cd}(\mathrm{II})$.
\end{abstract}

Keywords: Fast-scan anodic stripping voltammetry; Ultrasensitive determination; Cadmium(II); Bismuth-film electrode (Bi-FE)

\section{$\underline{\text { FULL TEXT }}$}

(C) 2018 The Authors. Published by ESG (www.electrochemsci.org). This article is an open access article distributed under the terms and conditions of the Creative Commons Attribution license (http://creativecommons.org/licenses/by/4.0/). 